\title{
Value of electrocardiogram in predicting and estimating infarct size in man
}

\author{
SALIM YUSUF, ROBERTO LOPEZ, ALAN MADDISON, PATRICIA MAW, \\ NILA RAY, SUSAN MCMILLAN, AND PETER SLEIGHT
}

From the Department of Cardiovascular Medicine, The Radcliffe Infirmary, University of Oxford

SUMMARY The value of the electrocardiogram in assessing infarct size was studied using serial estimates of the $\mathrm{MB}$ isomer of creatine kinase (CK MB) in plasma, serial 35 lead praecordial maps in 28 patients with anterior myocardial infarction, and serial 12 lead electrocardiograms in 17 patients with inferior myocardial infarction. In patients with anterior infarcts, $\Sigma S T, \Sigma R, \Sigma Q, \Sigma R / Q+S$ ), and the number of sites with ST elevation more than $2 \mathrm{~mm}$ or with QS waves, were obtained from each map. Correlation between both maximum $\Sigma \mathrm{Q}$ and maximum $\Sigma S T$ with cumulative $\mathrm{CK}$ MB was highly significant. There was also a significant correlation between $\Sigma R$ and $\Sigma R /(Q+S)$ with cumulative $C K$ MB. There was no significant correlation between maximum number of sites with ST elevation or with $\mathrm{Q}$ or QS waves and cumulative CK MB. Maximum $\Sigma S T$ and number of sites with ST elevation predicted maximum $\Sigma Q$ and number of sites with $Q S$ or $Q$ waves at a time when infarction was not complete. In patients with inferior infarcts, there was a significant correlation between maximum $\Sigma Q$ and maximum ¿ST in leads II, III, and aVF, and cumulative CK MB.

This study shows that all the waves in the electrocardiogram are useful in assessing infarct size. The fact that maximum $\Sigma S T$ predicts final $\Sigma Q$ may be used to assess the efficacy of interventions designed to salvage ischaemic myocardium.

It has been shown that the immediate and longterm prognosis after myocardial infarction is related to the quantity of necrotic myocardium (Sobel et al., 1972; Braunwald, 1976). Experiments in animals now indicate that the size of an infarct may be reduced by appropriate interventions (Maroko and Braunwald, 1973). However, the clinical assessment of interventions designed to protect ischaemic myocardium has posed considerable difficulty. Various techniques (Shell and Sobel, 1976; Bleifeld et al., 1977; Poliner et al., 1977; Muller et al., 1978) have been proposed for measuring and following trends in infarct size in patients.

Electrocardiographic mapping of the infarct from multiple praecordial sites has been proposed for this purpose (Muller et al., 1978). Considerable evidence has accumulated regarding its validity in the experimental situation (Wégria et al., 1949; Kjekshus et al., 1972; Maroko et al., 1972a, b; Hartman et al., 1975; Ross, 1976). However, it has been suggested on the basis of both theoretical evidence (Holland and Brooks, 1975, 1976; Fozzard and Das Gupta, 1976; Holland and Arnsdorf, 1977)

Received for publication 18 January 1979 and some clinical reports (Norris et al., 1976; Thompson and Katavatis, 1976) that the use of praecordial mapping to measure human infarct size has limited value. Most workers have assessed the value of individual waves of the electrocardiographic complex (Norris et al., 1976; Selwyn et al., 1977a, b) and there are few data on the QRS complex as a whole and its relation to ST segment changes in the same patient.

The present study was undertaken to investigate further the value of changes in the QRS complex and the ST segment elevation as a guide to infarct size in the coronary care unit. The main aims were to study the relation of the magnitude and extent of $Q$ wave development, $R$ wave loss, and $S T$ segment elevation to each other and to infarct size estimated by calculating the total release of the myocardial isoenzyme of creatine kinase (CK $\mathrm{MB}$ ) into the plasma.

\section{Patients}

Forty-five patients, aged between 46 and 75 years (mean 62.5 years), admitted to the coronary care unit (CCU) of the Radcliffe Infirmary with definite 
evidence of a recent myocardial infarction on a 12 lead electrocardiogram and significant increase in cardiac enzymes, were studied. Patients with intraventricular conduction defects (QRS duration $>100 \mathrm{~ms}$ ) including hemiblocks and second and third degree AV block were excluded. All patients had normal frontal axes $\left(0^{\circ}\right.$ to $\left.+90^{\circ}\right)$.

Of the 45 patients, 41 gave no history of a previous infarct, and a previous electrocardiogram was available in 14 of these. Twenty-eight patients had anterior infarcts and 17 inferior infarcts; none of the 4 with a history of previous infarction had pathological $Q$ waves on their initial electrocardiogram. Four patients later reinfarcted as shown by new electrocardiographic and enzyme changes. Routine management of the patient was not altered by the study procedure; diuretics and antiarrhythmic drugs were administered as clinically indicated. Lignocaine was given to 8 patients, 11 patients received oral beta-blockers, and disopyramide was used in only 1 patient. No patient had a systolic blood pressure less than $90 \mathrm{mmHg}$. Three patients required cardioversion for ventricular fibrillation, none of whom showed a further rise in CK MB.

\section{Methods}

\section{PRAECORDIAL ELECTROCARDIOGRAPHIC MAPPING}

Praecordial electrocardiographic mapping was done in all patients with anterior myocardial infarction. Thirty-five praecordial sites were selected by focusing an ordinary projector beam through a $35 \mathrm{~mm}$ slide with 35 holes arranged in 5 horizontal rows and 7 vertical rows. The horizontal rows were designated from top to bottom $A$ to $E$ and the vertical rows from right to left 1 to 7 . The distance between the first and second vertical rows was twice the distance between the others to avoid electrode placement on the sternum. With the patient sitting up at 45 degrees, A1 was focused on a point $2.5 \mathrm{~cm}$ to the right of the sternal edge in the second intercostal space. E1 was focused $2 \mathrm{~cm}$ below the level of the xiphisternum in the same line as Al. The position of the projector was adjusted so that $A 7$ fell on a spot high in the left midaxillary line in such a way that rows A to $E$ were horizontally placed. All the spots were then marked using indelible ink to allow accurate repositioning of the electrodes each time a recording was obtained.

The electrocardiograms were recorded using a four-channel ink-jet Elema-Schönander Mingograf 34 recorder. Suction cup electrodes with a contact diameter of $15 \mathrm{~mm}$ were used. The electrocardiogram was recorded from each praecordial site at 2 different gains simultaneously $(1 \mathrm{mV}=10 \mathrm{~mm}$ and
$1 \mathrm{mV}=40 \mathrm{~mm}$ ) so that an accuracy of $0.025 \mathrm{mV}$ could be obtained. Paper speed was $25 \mathrm{~mm} / \mathrm{s}$.

Each recording was made during quiet breathing and great care was taken to reposition the patient at the same angle on each occasion. The first recording was obtained at a mean time of 6 hours after the onset of pain (at less than 4 hours in 19 patients, at 4 to 6 hours in 12 patients, at 6 to 12 hours in 10 patients, and at more than 12 hours in 4 patients). Subsequently, recordings were obtained at 8-hour intervals during the first 24 hours, at 12-hour intervals on the second day, and thereafter daily.

Initial studies showed that praecordial electrocardiographic mapping was of limited value in inferior infarction. Therefore, in order to record changes from the inferior surface of the heart, the standard 12 lead electrocardiogram was recorded serially, the $\mathrm{V}$ lead positions being marked on the chest wall to obtain reproducible recordings.

\section{ELECTROCARDIOGRAPHIC MEASUREMENTS Anterior infarct patients}

The amplitude of the $Q, R$, and $S$ waves, and of ST segment elevation (at $60 \mathrm{~ms}$ after the $\mathrm{J}$ point) was measured in 5 beats from each site, using the TP segment as a baseline. Measurements were made on both the magnified $(1 \mathrm{mV}=40 \mathrm{~mm})$ and regular recordings $(1 \mathrm{mV}=10 \mathrm{~mm})$. These were then summed from 35 leads to obtain $\Sigma \mathrm{R}, \Sigma \mathrm{Q}, \Sigma \mathrm{S}$, and $\Sigma S T$. In addition, $\Sigma(\mathrm{Q}+\mathrm{S})$ and $\Sigma \mathrm{R} / \Sigma(\mathrm{Q}+\mathrm{S})$ were calculated for each map.

\section{Inferior infarct patients}

In patients with inferior infarction, $\mathrm{QII}+\mathrm{III}+\mathrm{aVF}$ and ST segment elevations in II $+\mathrm{III}+\mathrm{aVF}$ were calculated.

SERIAL CK AND CK MB ANALYSES

Blood samples were obtained from a peripheral vein through an indwelling cannula at 4-hourly intervals for 72 hours after the onset of pain. Samples were immediately centrifuged for 15 minutes. Plasma was pipetted into plain sterile glass tubes and stored at $-20^{\circ} \mathrm{C}$. $\mathrm{CK}$ was estimated using the method of Oliver (1955) with dithiothreital as activator as utilised by the Searle CPK$U_{11}$ kit. The method described by Mercer and Varat (1975) was used to separate the CK isoenzymes.

\section{$C K M B$ and mathematical calculations}

The appearance function of $\mathrm{CK} M B$ released from the infarcted myocardium was calculated (cumulative CK MB) by the method described by Sobel et al. (1972) and modified by Norris et al. (1975). 
REPRODUCIBILITY STUDIES IN CONTROL SUBJECTS

Twenty normal subjects between the ages of 30 and 70 years, and 5 patients 2 to 4 weeks after infarction, likely to have a stable electrocardiographic pattern, were studied to confirm the reproducibility of praecordial mapping and the standard 12 lead clectrocardiogram. Recordings were examined for beat-to-beat variations during sinus rhythm and atrial fibrillation, variations during quiet and deep breathing, variations caused by electrode repositioning, and those resulting from changes in patient position.

The beat-to-beat variation of measurements of the QRS complex and of ST segment elevation in the same recording during sinus rhythm was small (mean $2.2 \%$ ), compared with a mean of 15 per cent and 20 per cent in 2 patients who were in atrial fibrillation. The variations resulting from changes in posture and during deep breathing were considerable (mean $12 \cdot 12 \%$ and $18.5 \%$, respectively). In contrast, the variation caused by electrode repositioning, day-to-day variation, and variation during quiet breathing with the patient at 45 degrees and in sinus rhythm was less than 5.3 per cent. All patients were in sinus rhythm except 2 who were in atrial fibrillation in whom 10 consecutive beats were averaged.

\section{Results}

RELATION BETWEEN CUMULATIVE CK MB AND PRAECORDIAL MAP IN PATIENTS WITH ANTERIOR INFARCTION

ST segment elevation (Fig. 1)

The maximum $\Sigma S T$ observed during the first 3 days was found to correlate significantly with cumulative $\mathrm{CK} \mathrm{MB} \mathrm{(}=0.733 ; \mathrm{P}<0.001)$. There was no significant correlation between $\Sigma S T$ at any other time and cumulative $\mathrm{CK} M B$. The maximum number of recording sites with ST segment elevation more than $1 \mathrm{~mm}$ or more than $2 \mathrm{~mm}$ also did not correlate with cumulative CK MB.

\section{$Q$ waves}

Correlation between the maximum $\Sigma Q$ and cumulative CK MB was highly significant ( $r=$ $0.827 ; P<0.001 ;$ Fig. 2). No correlation was observed between the number of recording sites showing pathological $Q$ waves $(r=0.265 ; P>0.1)$, or $Q S$ waves $(r=0.363 ; P>0.1)$ and cumulative CK MB.

$R$ wave and $R /(Q+S)$ ratio

The inverse relations between minimal $\Sigma R$ (Fig. 3) and minimal $\Sigma R /(Q+S)$, and cumulative $C K M B$

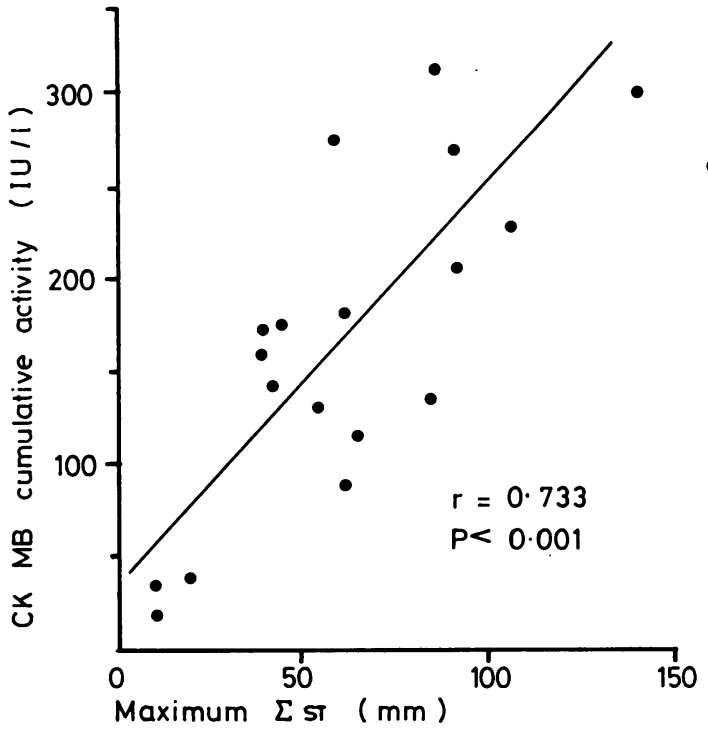

Fig. 1 Maximum $\Sigma S T$ from the praecordial map is plotted against cumulative release of $C K M B$ in patients with anterior infarction. A good correlation is seen.

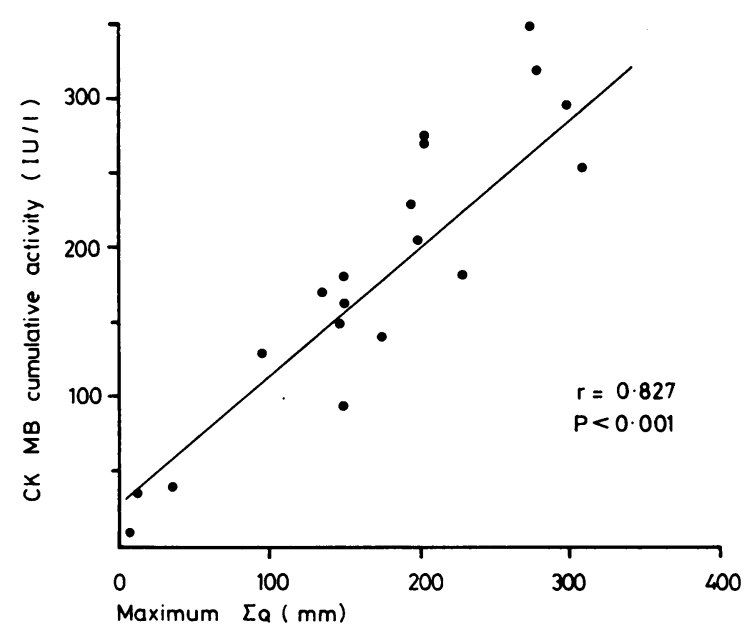

Fig. 2 Maximum $\Sigma Q$ is plotted against cumulative release of $C K M B$ in patients with anterior infarction. $A$ highly significant correlation is seen.

were less significant $(\mathrm{r}=-0.623 ; \mathrm{P}<0.01$ and $\mathrm{r}=$ $-0.624 ; P<0.01$, respectively) than the relation between maximum $\Sigma \mathrm{Q}$ and cumulative $\mathrm{CK} M B$.

\section{INFERIOR INFARCTION}

Preliminary studies not surprisingly failed to show any significant relation between infarct size estimated from CK MB and the praecordial electro- 


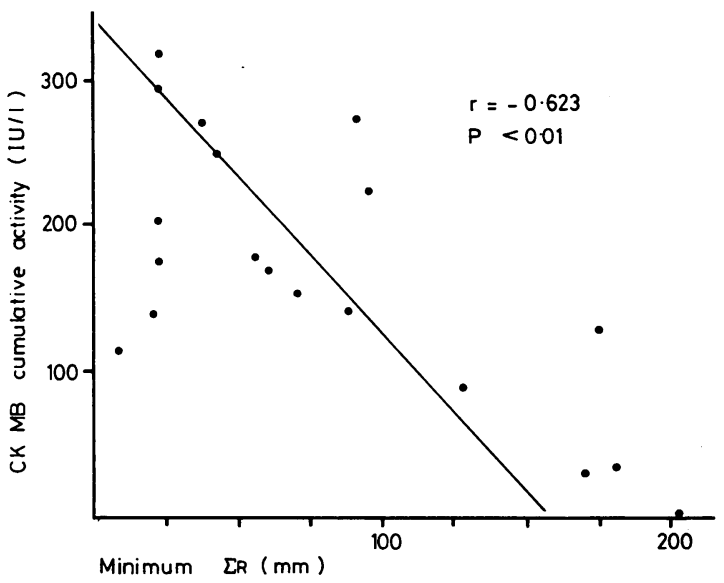

Fig. 3 Minimum $\Sigma R$ is plotted against cumulative release of $C K M B$ in patients with anterior infarction. $A$ fair correlation is seen.

cardiogram in patients with inferior myocardial infarction. However, the sum of the ST segment elevations and of $Q$ wave amplitudes in leads II+ III + aVF correlated with cumulative $\mathrm{CK} M B$ $(r=0.505 ; P<0.05$ and $r=0.745 ; P<0.01$, respectively; Fig. 4). There was no significant relation between the sum of $R$ wave amplitudes in leads $\mathrm{II}+\mathrm{III}+\mathrm{aVF}$ and cumulative CK $\mathrm{MB}$.

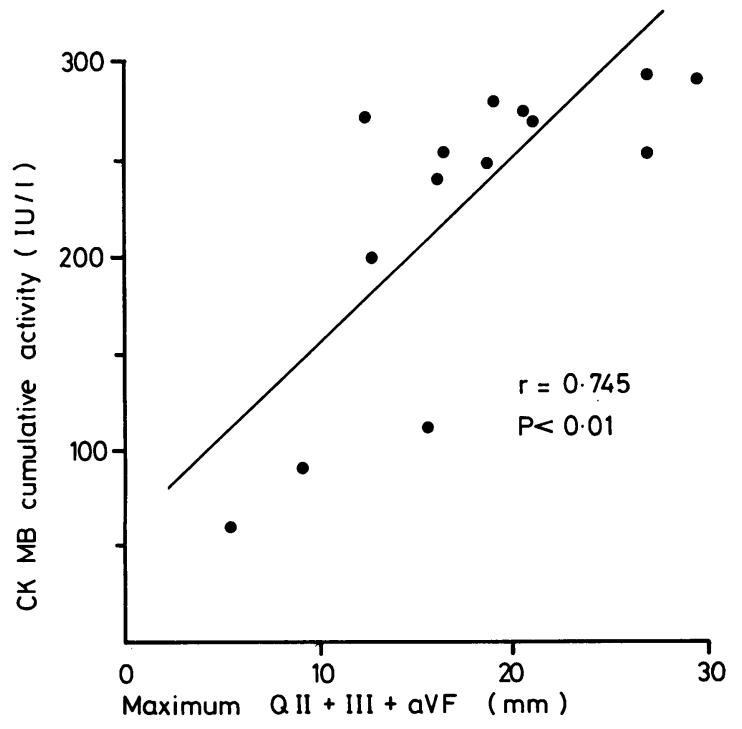

Fig. 4 Maximum $Q I I+I I I+a V F$ is plotted against cumulative release of $C K M B$ in patients with inferior infarction. A fair correlation is seen.
INTERRELATION OF WAVES IN

ELECTROCARDIOGRAM

In patients with anterior infarcts, the maximum $\Sigma S T$ was found to predict maximum $\Sigma Q$ at a time when electrocardiographic evolution of infarction was not complete $(r=0.820 ; P<0.001 ;$ Fig. 5$)$. The number of sites with ST segment elevation more than $1 \mathrm{~mm}$ and sites with ST segment elevation more than $2 \mathrm{~mm}$ predicted the number of sites developing QS waves $(r=0.602 ; P<0.01$, and $r=0.635 ; P<0.01$, respectively; Fig. 6). In addition, in individual patients the maximum ST segment elevation recorded at each of the 35 sites correlated well with final $Q$ wave and final $R$ wave amplitude at the same

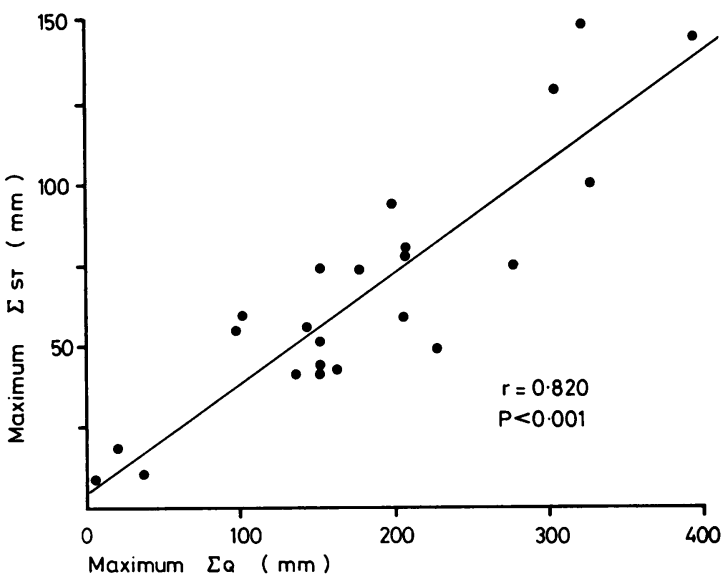

Fig. 5 Maximum $\Sigma S T$ is plotted against maximum $\Sigma Q$ in patients with anterior infarction. A good correlation is seen.

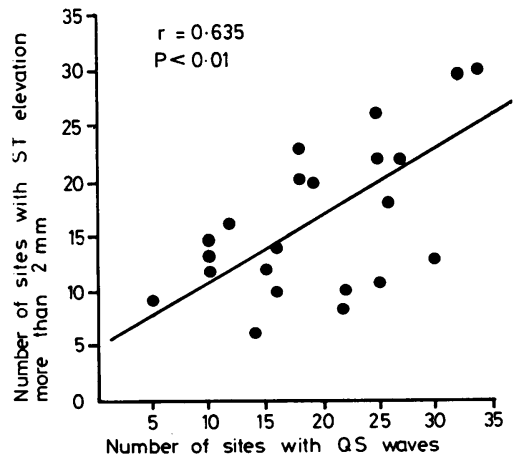

Fig. 6 The number of sites with $S T$ segment elevation more than $2 \mathrm{~mm}$ is plotted against the number of sites with $Q S$ waves in patients with anterior infarction. $A$ fair correlation is seen. 
site $(r=0.764 ; P<0.001$, and $r=-0.746 ; P<0.001$, respectively). Maximum $\Sigma Q$, not unexpectedly, correlated inversely with minimum $\Sigma \mathbf{R}$ in patients with anterior infarcts $(r=-0.824 ; P<0.001)$.

There was no relation between maximum ST segment elevation and maximum $Q$ II + III $+a V F$ in patients with inferior infarcts.

\section{Discussion}

Since Maroko and Braunwald (1973) first described ST segment mapping, considerable interest has been focused on the electrocardiographic method for estimating infarct size. Experimental work in dogs with coronary artery occlusion (Maroko et al., 1972a, b) established the validity of the method. In their animal experiments, the site and, to a certain extent, the size of the infarction was determined by the site of occlusion of a particular coronary artery. However, in the clinical situation, varying sizes of infarct are encountered, more than one wall of the heart may be involved, and evolution of the infarct may be more variable in time (Yusuf et al., 1978).

The development of the enzyme method of estimation of infarct size has provided the clinician with another index of the extent of infarction. Electrocardiographic assessment may be influenced by factors other than infarct size, such as site of infarct, presence of arrhythmias or conduction defects, or changes in local ion concentration; the enzyme method does not have these drawbacks. The amount of CK released has been shown to bear a close relation to total $\mathrm{CK}$ depletion in rabbits (Kjekshus and Sobel, 1970), and to infarct size measured morphologically at necropsy in patients who died of acute myocardial infarction (Bleifeld $e t$ al., 1977). Though the model for the basis for calculation of infarct size from enzymes has been criticised (Roe et al., 1977), the enzyme method nevertheless provides an empirical estimate of infarct size by a totally independent method, with which electrocardiographic assessment of infarct size can be usefully compared.

\section{ST SEGMENT ELEVATION}

The relation of praecordial ST segment elevation to histological and biochemical estimates of the extent of myocardial necrosis is well documented in experimental investigations on animals (Kjekshus et al., 1972; Maroko et al., 1972a, b). However, the relation of ST segment elevation to other estimates of infarct size in man is controversial. Morris et al. (1974) showed that ST segment elevation 48 hours after the onset of pain correlated with maximal AST (SGOT) in patients with anterior or inferior infarcts.
Blomqvist et al. (1975) showed that there was a significant correlation between $\Sigma S T$ and the area of an infarct as determined by pyrophosphate scan. By contrast, Norris et al. (1976), Thompson and Katavatis (1976), and Selwyn et al. (1977a) showed no correlation or at best weak correlation between ST segment elevation and peak or total plasma enzyme.

In our study we have observed a strong positive correlation between maximum $\Sigma S T$ and cumulative CK MB $(r=0.733 ; P<0.001)$ in patients with anterior infarcts, and a weaker but significant correlation in inferior infarcts using the sum of ST segment elevation in leads II, III, and aVF $(r=0.505 ; \quad P<0.05)$. Several factors may be responsible for the different results obtained by different workers. Firstly, praecordial mapping reflects only changes affecting the anterior and anterolateral wall of the left ventricle and it is possible that in some studies the patients may have had involvement of other walls of the heart. In our study, none of the patients with anterior infarction had any fresh electrocardiographic changes in the inferior leads, though a small true posterior infarct may have been undetected. Secondly, variations in chest shape and size and localisation of infarction may lead to differences between patients. Thirdly, ST segment elevation is known to increase or decrease rapidly in some patients (Selwyn et al., 1977a) and variable intervals between onset of pain and time of electrocardiographic recording will introduce further error. To minimise this source of error we have taken recordings at regular intervals in all our patients.

\section{R WAVE}

A decrease in the amplitude of $\mathbf{R}$ waves during experimental myocardial infarction was reported by Wilson et al. (1935). Muller et al. (1978) showed a good correlation between loss of $R$ wave amplitude and infarct size in experimental infarction. Recently, Selwyn et al. (1977b) have demonstrated a good correlation with estimates of infarct size from CK release.

In our study, we have observed only a fair inverse correlation between minimal $\Sigma \mathrm{R}$ and cumulative CK $M B$ release $(r=-0.623 ; P<0.01)$. This may be partly the result of the large variation in $\Sigma \mathbf{R}$ observed in our control group of normals ( $\Sigma R$ varies from 150 to $300 \mathrm{~mm}$ ). Though this may limit the value of $\Sigma R$ in comparing infarct size in different patients, it is still useful in following the course of infarction in an individual patient (Yusuf et al., 1978), and in comparing infarct size in 2 large groups. 


\section{Q WAVE}

Myers et al. (1948a, b; 1949) described an excellent correlation between the development of $Q$ waves in specific praecordial leads and pathological evidence of infarction in the corresponding areas of the heart. Similarly, in patients undergoing cardiac surgery, it has been shown that praecordial $Q$ waves generally overlie epicardial $Q$ waves and that these indicate the presence of myocardial fibrosis (Bodenheimer et al., 1976). In addition, a close correlation between praecordial $Q$ waves and ventricular performance in patients with coronary artery disease has been reported (Miller et al., 1972; Williams et al., 1973; Miller et al., 1974; Awan et al., 1977).

These observations are consistent with our finding that $\Sigma Q$ from praecordial maps correlates well with cumulative $\mathrm{CK} M B$ in patients with anterior infarcts $(r=0.827 ; P<0.001)$. The range of variation of $\Sigma Q$ in our control group was between 0 and $12 \mathrm{~mm}$ in the 35 lead map. In contrast, $\Sigma Q$ in most patients with anterior infarcts was several times greater. Though the correlation between $\mathrm{QII}+\mathrm{III}+\mathrm{aVF}$ and cumulative CK $\mathrm{MB}$ in patients with inferior infarcts is less impressive $(r=0.745$; $\mathbf{P}<0.01$ ), this is hardly surprising as these data were obtained from 3 electrocardiographic leads only. This may detract from its value in comparing infarct size in different patients but QII + III + aVF is useful in comparing groups of patients and in studying the evolution of an infarct (unpublished data).

\section{RELATION OF NUMBER OF SITES WITH}

ELECTROCARDIOGRAPHIC ABNORMALITIES TO CUMULATIVE CK MB

Although several workers have used the number of sites (or area) with ST segment elevation or pathological $Q$ wave development as an index of the extent of ischaemia or necrosis and to evaluate the efficacy of interventions (Maroko et al., 1972a, b; Muller et al., 1975; Selwyn et al., 1977a, b; 1978), we found no relation between the number of sites with ST segment elevation greater than $2 \mathrm{~mm}$, ST segment elevation of any degree, or pathological Q or QS waves, and enzyme estimates of infarct size. A similar experience was reported by Nielsen (1973), who observed that the sum of ST segment elevations from an ordinary 12 lead electrocardiogram was a good prognostic indicator, whereas the number of leads with ST segment elevation was not related to prognosis. This is not surprising as the number of sites showing abnormalities does not provide information about the magnitude of change at a particular praecordial site. We believe, therefore, that $\Sigma S T$ or $\Sigma Q$ are better indices of infarct size than the number of sites with abnormalities.

\section{PREDICTION OF INFARCT SIZE}

In patients with anterior infarcts, maximum $\Sigma S T$ has been shown to be related to final $\Sigma Q$ and $\Sigma R$, and one could therefore use this measurement to predict infarct size. This relation could also be exploited in assessing interventions aimed at decreasing infarct size, as the slope of the line relating $\Sigma S T$ and $\Sigma Q$ would be difficult in control subjects and in subjects on beneficial treatment. Henning et al. (1978) have used a formula based on $\Sigma S T$ obtained from the first map and the rate of loss of $\mathbf{R}$ wave amplitude to predict cumulative CK MB. However, these authors stress that this observation was made in a highly selected group of patients. We have also shown a relation between number of sites with ST segment elevation and those with QS waves. This confirms the work of Askenazi et al. (1977) and supports the view that the number of sites with ST segment elevation can be used to predict $Q$ wave extent.

We observed no significant relation between the sum of ST segment elevations in II, III, and aVF, and QII + III + aVF in patients with inferior infarcts.

In conclusion, measurements of ST segment elevation, $Q$ wave development, and $R$ wave loss from praecordial maps, can all be used to assess infarct size in patients with anterior infarcts. Measurements of $Q$ waves and ST segment elevation in leads II, III, and aVF also provide useful but less accurate information about infarct size in patients with inferior infarcts.

The authors are grateful to Dr. R. M. Norris for his criticism and help in the preparation of this manuscript.

This work was carried out with the aid of a grant from the British Heart Foundation.

\section{References}

Askenazi, J., Maroko, P. R., Lesch, M., and Braunwald, E. (1977). Usefulness of ST segment elevations as predictors of electrocardiographic signs of necrosis in patients with acute myocardial infarction. British Heart fournal, 39, 764-770.

Awan, N., Miller, R. R., Vera, Z., Janzen, D., Amsterdam, E. A., and Mason, D. T. (1977). Noninvasive assessment of cardiac function and ventricular dyssynergy by praecordial $\mathrm{Q}$ wave mapping in anterior myocardial infarction. Circulation, 55, 833-838.

Bleifeld, W., Mathey, D., Hanrath, P., Buss, H., and Effert, S. (1977). Infarct size estimated from serial serum creatine phosphokinase in relation to left ventricular haemodynamics. Circulation, 55, 303-311.

Blomqvist, C. G., Peshock, R., Parkey, R. W., Bonte, F. J., and Willerson, J. T. (1975). ST isopotential praecordial surface mapping in acute myocardial infarction (abstract). Circulation, 51 and 52, Suppl. II, 108. 
Bodenheimer, M. M., Banka, V. S., Trout, R. G., Herman, G. A., and Helfant, R. H. (1976). Correlation of pathologic $Q$ waves on the standard electrocardiogram and the epicardial electrogram of the human heart. Circulation, 54, 213-218.

Braunwald, E. (1976). Introductory remarks. Symposium on protection of the ischemic myocardium. Circulation, 53 and 54, Suppl. I, 1-2.

Fozzard, H. A., and Das Gupta, D. S. (1976). ST segment mapping: theory and experiment. Circulation, 54, 533-537.

Hartman, J., Robinson, J., and Geanar, R. (1975). Infarct size and chemotactic activity: comparison of decomplementation and enzyme inhibition (abstract). Circulation, 51 and 52, Suppl. II, 22.

Henning, H., Hardarson, H., Francis, G., O'Rourke, A. R., Ryan, W., and Ross, J., jun (1978). Approach to the estimation of myocardial infarct size by analysis of praecordial ST segment and R wave maps. American fournal of Cardiology, 41, 1-7.

Holland, R. P., and Arnsdorf, M. R. (1977). Solid angle theory and the electrocardiogram: physiologic and quantitative interpretations. Progress in Cardiovascular Diseases, 19, 430-457.

Holland, R. P., and Brookes, H. (1975). Praecordial and epicardial surface potentials during myocardial ischaemia in pigs. Circulation Research, 37, 471-480.

Holland, R. P., and Brooks, H. (1976). The QRS complex during myocardial ischaemia. fournal of Clinical Investigation, 57, 541-550.

Kjekshus, J. K., Maroko, P. R., and Sobel, B. E. (1972). Distribution of myocardial injury and its relation to epicardial ST segment changes after coronary artery occlusion in the dog. Cardiovascular Research, 6, 490-499.

Kjekshus, J. K., and Sobel, B. E. (1970). Depressed myocardial creatine phosphokinase activity following experimental myocardial infarction in rabbit. Circulation Research, 27, 403-414.

Maroko, P. R., and Braunwald, E. (1973). Modification of myocardial infarction size after coronary occlusion. Annals of Internal Medicine, 79, 720-733.

Maroko, P. R., Libby, P., Covell, J. W., Sobel, B. E., Ross, J., jun., and Braunwald, E. (1972a). Praecordial ST segment elevation mapping: an atraumatic method for assessing alterations in the extent of myocardial ischaemic injury. American fournal of Cardiology, 29, 223-230.

Maroko, P. R., Libby, P., Ginks, W. R., Bloor, C. M., Shell, W. E., Sobel, B. E., and Ross, J., jun. (1972b). Coronary artery perfusion. I Early effects on local myocardial function and the extent of myocardial necrosis. Fournal of Clinical Investigation, 51, 2710-2716.

Mercer, D. W., and Varat, M. A. (1975). Detection of cardiacspecific creatine kinase isoenzyme in sera with normal or slightly increased total creatine kinase activity. Clinical Chemistry, 21, 1088-1092.

Miller, R. R., Amsterdam, E. A., Bogren, H. G., Massumi, R. A., Zelis, R., and Mason, D. T. (1974). Electrocardiographic and cineangiographic correlations in assessment of the location and nature and extent of abnormal left ventricular segmental contraction in coronary artery disease. Circulation, 49, 447-454.

Miller, R. R., Bonanno, J., Massumi, R. A., Zelis, R., Mason, D. T., and Amsterdam, E. A. (1972). Usefulness of the electrocardiogram in assessment of ventricular performance and comparison with coronary arteriograph (abstract). American fournal of Cardiology, 29, 281-288.

Morris, G. K., Hampton, J. R., Hayes, M. J., and Mitchell, J. R. A. (1974). Predictive value of ST segment displacement and other indices after myocardial infarction. Lancet, 2, 372-374

Muller, J. E., Maroko, P. R., and Braunwald, E. (1975).
Evaluation of praecordial electrocardiographic mapping as a means of assessing changes in myocardial ischemic injury. Circulation, 52, 16-27.

Muller, J. E., Maroko, P. R., and Braunwald, E. (1978). Praecordial electrocardiographic mapping. Circulation, 57, $1-18$.

Myers, G. B., Klein, H. A., and Hiratzka, T. (1948a). II. Correlation of electrocardiographic and pathologic findings in large anterolateral infarcts. American Heart fournal, 36, 838-881.

Myers, G. B., Klein, H. A., and Stofer, B. E. (1948b). I. Correlation of electrocardiographic and pathological findings in anteroseptal infarction. American Heart fournal, 36, 535-575.

Myers, G. B., Klein, H. A., and Stofer, B. E. (1949). VII. Correlation of electrocardiogram and pathologic findings in lateral infarction. American Heart fournal, 37, 374-417.

Nielsen, B. L. (1973). ST segment elevation in acute myocardial infarction. Prognostic importance. Circulation, 48, 338-345.

Norris, R. M., Barratt-Boyes, C., Heng, M. K., and Singh, B. N. (1976). Failure of ST segment elevation to predict severity of acute myocardial infarction. British Heart fournal, 38, 85-92.

Norris, R. M., Whitlock, R. M. L., Barratt-Boyes, C., and Small, C. W. (1975). Clinical measurement of myocardial infarct size: modification of a method for the estimation of creatine phosphokinase release after myocardial infarction. Circulation, 51, 614-620.

Oliver, I. T. (1955). A spectrophotometric method for the determination of creatine phosphokinase and myokinase. Biochemical fournal, 61, 116-122.

Poliner, L. R., Buja, M. L., Parkey, R. W., Stokeley, E. M., Stone, M. J., Harris, R., Saffer, S. W., Templeton, G. H., Bonte, F. J., and Willerson, J. T. (1977). Comparison of different non-invasive methods of infarct sizine during experimental myocardial infarction. Fournal of Nuclear Medicine, 18, 517-523.

Roe, C. R., Cobb, F. R., and Starmer, C. F. (1977). The relationship between enzymatic and histologic estimates of the extent of myocardial infarction in conscious dogs with permanent coronary occlusion. Circulation, 55, 438-449.

Ross, J., jun. (1976). Electrocardiographic ST segment analysis in the characterisation of myocardial ischemia and infarction. Circulation, 53, Suppl. I, 73-81.

Selwyn, A. P., Fox, K., Welman, E., and Shillingford, J. P. (1978). Natural history and evaluation of $Q$ waves during myocardial infarction. British Heart fournal, 40, 383-387.

Selwyn, A. P., Ogunro, E., and Shillingford, J. P. (1977a). Natural history and evolution of ST segment changes and MB-CK release in acute myocardial infarction. British Heart fournal, 39, 988-994.

Selwyn, A. P., Ogunro, E., and Shillingford, J. P. (1977b). Loss of electrically active myocardium during anterior infarction in man. British Heart fournal, 39, 1186-1191.

Selwyn, A. P., and Shillingford, J. P. (1977). Praecordial mapping of $Q$ waves and $R S$ ratio changes in acute myocardial infarction. Cardiovascular Research, 11, 167-171.

Shell, W. E., and Sobel, B. E. (1976). Biochemical markers of ischemic injury. Circulation, 53, 98-105.

Sobel, B. E., Bresnahan, G. F., Shell, W. E., and Yoder, R. D. (1972). Estimation of infarct size in man and its relation to prognosis. Circulation, 46, 640-648.

Thompson, P. L., and Katavatis, V. (1976). Acute myocardial infarction: evaluation of praecordial ST segment mapping. British Heart fournal, 38, 1020-1024.

Wégria, R., Segers, M., Keating, R. P., and Ward, H. P. (1949). Relationship between the reduction in coronary flow and the appearance of electrocardiographic changes. American Heart fournal, 38, 90-96. 
Williams, R. A., Cohn, P. F., Vokonas, P. S., Young, E., Herman, M. V., and Gorlin, R. (1973). Electrocardiographic, arteriographic and ventriculographic correlations in transmural myocardial infarction. American fournal of Cardiology, 31, 595-599.

Wilson, F. N., Johnston, F. D., and Hill, I. G. W. (1935). The form of the electrocardiogram in experimental myocardial infarction. IV. Additional observations in the later effects produced by ligation of the anterior descending branch of the left coronary artery. American Heart fournal,
10, 1025-1041.

Yusuf, S., Lopez, R., Maddison, A., and Sleight, P. (1978). Electrocardiographic and enzyme evolution of infarct size in man. Circulation, 57, and 58, Suppl. II, Abstract 172.

Requests for reprints to Dr Salim Yusuf, Department of Cardiovascular Medicine, The John Radcliffe Hospitals, Headington, Oxford OX3 9DU. 